\title{
SKRINING VIRTUAL DAN PENAMBATAN MOLEKUL SEBAGAI METODE PEMILIHAN PENGGUNAAN OBAT YANG SUDAH ADA (REPURPOSING DRUG) KANDIDAT TERAPI COVID-19
}

\author{
I Gede Ari Sumartha1, Tegar Achsendo Yuniarta2 ${ }^{2}$ I Putu Gede Adi Purwa Hita ${ }^{3}$ \\ 1,2) Departemen Kimia Farmasi, Fakultas Farmasi, Universitas Surabaya \\ 3) Universitas Bali Internasional, Jl. Seroja Denpasar - Bali 80114 \\ e-mail: 1) igedearisumartha@staff.ubaya.ac.id \\ 2) tegar.achsendo@staff.ubaya.ac.id \\ 3) adipurwah.1@gmail.com
}

\begin{abstract}
ABSTRAK
COVID 19 merupakan penyakit yang mematikan dan masih belum ditemukan obatnya. Penelitian terhadap obat baru hingga dapat diedarkan membutuhkan waktu yang lama, sehingga penggunaan obat yang sudah ada dapat dijadikan alternatif terhadap terapi COVID 19. Metode skrining virtual dan penambatan molekul dapat dijadikan salah satu metode untuk mendapatkan pilihan dari pangkalan data obat-obat yang FDA-approved. Skrining virtual dengan metode electroshape diharapkan mendapatkan obat-obat dengan sifat yang sama seperti obat yang sudah terbukti secara in vitro menghambat enzim Mpro. Validasi metode perlu dilakukan terlebih dahulu sebelum dilakukan penambatan molekul dari obat-obat hasil skrining dengan menggunakan senyawa perangkap. Hasil validasi didapatkan kurva ROC sebesar 0,900 yang merupakan hasil validasi yang baik. Setelah dilakukan penambatan molekul obat-obat hasil skrining didapatkan dua obat dengan binding affinity yang lebih rendah dari senyawa penuntunnya yaitu natamycin dan pitavastatin.
\end{abstract}

Kata kunci: COVID 19, skrining virtual, penggunaan obat yang sudah ada

\section{ABSTRACT}

COVID 19 is a deadly disease and there is still no cure. Research on new drugs takes a long time so that repurposing drugs can be used as an alternative to COVID 19 therapy. Virtual screening and molecular docking methods can be used to get choices from the FDA-approved drug database. Virtual screening with electroshape method is expected to get drugs with the same properties as drugs proven in vitro to inhibit the Mpro enzyme. Validation of the method needs to be done before docking the molecules of the screening drugs using a decoy compound. The validation results obtained a ROC curve of 0.900, which is a good validation result. After docking the molecules of the screening drugs, two drugs with a lower binding affinity than the guiding compounds were obtained, namely natamycin and pitavastatin.

Keywords: COVID 19, virtual screening, drug reuse 
MEDFARM: Jurnal Farmasi dan Kesehatan, Vol.10, No.2, Des 2021, Hal, 65-74

e-ISSN : 2715-9957

p-ISSN: 2354-8487

\section{PENDAHULUAN}

COVID 19 merupakan penyakit mematikan dan sangat mudah menular (Wu et al., 2020). Hingga saat ini penanganan terhadap COVID 19 di Indonesia terbatas pada penggunaan obat antivirus lainnya seperti favipiravir, remdesivir dan lain sebagainya (BPOM, 2020). Penggunaan obat yang sudah ada (repurposing drug) yang telah mendapatkan ijin edar dengan indikasi berbeda merupakan tindakan yang paling cepat untuk dilakukan untuk menangani wabah yang cepat menular seperti COVID 19 (Cusinato et al., 2021). Hal ini disebabkan karena pengembangan obat membutuhkan waktu yang cukup lama hingga dapat diedarkan.

Salah satu metode yang dapat digunakan dalam melakukan penggunaan obat yang sudah ada yang sudah mendapatkan ijin edar adalah dengan skrining secara virtual lalu dilakukan penambatan molekul (Sekhar, 2020). Kita dapat menggunakan kemiripan dari struktur senyawa hasil penelitian yang berhasil menghambat enzim Mpro dari COVID 19 seperti boceprevir (Qiao et al., 2021). Mpro atau Main protease adalah salah satu enzim yang dapat memediasi transkripsi protein dari COVID 19 sehingga hambatan terhadap enzim ini diharapkan akan menghambat kelangsungan hidup dari virus (Zang et al., 2020). Metode skrining dengan electroshape digunakan untuk memperoleh senyawa obat yang memiliki kemiripan dengan boceprevir yang diterapkan pada pangkalan data obat-obat yang sudah FDA-approved. Metode tersebut dikatakan mampu mendapatkan data senyawa hasil skrining yang baik karena memperhitungkan bentuk 3 dimensi, muatan parsial dan lipofilisitas atom (Armstrong et al., 2011). Lalu pada studi ini, senyawa senyawa obat hasil skrining tersebut akan dilakukan penambatan molekul yang hasilnya berupa binding affinity sebagai parameter dalam penentuan aktivitas senyawa senyawa yang ditambatkan.

\section{METODOLOGI PENELITIAN}

\section{Skrining virtual}

Senyawa boceprevir diambil dengan cara mengekstrak data ligan pada webserver Protein Data Bank (https://www.rcsb.org) . Enzim yang digunakan 
MEDFARM: Jurnal Farmasi dan Kesehatan, Vol.10, No.2, Des 2021, Hal, 65-74

e-ISSN : 2715-9957

p-ISSN: 2354-8487

adalah enzim dengan PDB ID 7COM (Qiao et al., 2021). Setelah data ligan boceprevir diekstrak lalu disimpan dalam bentuk .smiles yang kemudian diinputkan ke webserver SwissSimiliarity (http://www.swisssimilarity.ch) (Zoete et al., 2016). Pangkalan data yang digunakan adalah data obat yang sudah approved dengan metode skrining electroshape. Setelah skrining data dapat diambil dalam file .csv yang kemudian digambarkan strukturnya menggunakan aplikasi MarvinSketch 20.21 (http://www.chemaxon.com) dan disimpan dalam .mol2.

\section{Validasi metode penambatan molekul}

Data .smiles dari boceprevir dimasukkan ke dalam webserver DUD-E (http://dude.docking.org) untuk memperoleh data senyawa perangkap yang diduga tidak memiliki aktivias terhadap enzim yang dipilih (Mysinger et al., 2012). Setelah didapatkan data senyawa perangkap kemudian digambarkan menggunakan aplikasi Marvinsketch 20.21 (http://www.chemaxon.com) yang kemudian disimpan dalam bentuk .mol2. Preparasi dan penambatan molekul senyawa perangkap dan ligan dilakukan menggunakan EasyDockVina 2.2 (Eltijani et al., 2019). Untuk mendapatkan data grid box, digunakan AutoDockTools 1.5.6 yang kemudian diperoleh gridcenter $\mathrm{x}=-21.411, \mathrm{y}=5.817, \mathrm{z}$ $=29.334$ dengan gridsize $\mathrm{x}=16, \mathrm{y}=16, \mathrm{z}=16$ dengan spacing sudah default yaitu 1.000 Angstrom. Kemudian hasil penanambatan dilakukan analisa ROC menggunakan webserver screening explorer (http://stats.drugdesign.fr). Apabila nilai ROC lebih dari 0,5 maka metode yang dilakukan dapat dikatakan valid (Triballeau et al., 2005).

\section{Penambatan molekul senyawa hasil skrining}

Senyawa hasil skrining diawal dipreparasi dan ditambatkan pada enzim dengan cara yang sama seperti pada validasi metode. Ukuran gridbox juga menyesuaikan dengan validasi metode yang sudah dilakukan. Setelah itu dianalisa hasil penambatan molekul berdasarkan binding affinity nya. 
MEDFARM: Jurnal Farmasi dan Kesehatan, Vol.10, No.2, Des 2021, Hal, 65-74

e-ISSN : 2715-9957

p-ISSN: 2354-8487

\section{HASIL DAN PEMBAHASAN}

Dari hasil skrining virtual didapatkan 53 senyawa obat yang dikatakan mirip dengan tingkat kemiripan 0,824 sampai 0,700 berdasarkan metode electroshape.

Tabel 1. Hasil skrining virtual senyawa mirip boceprevir dengan pangkalan data FDA-approved dan metode skrining electroshape.

\begin{tabular}{|c|c|c|}
\hline $\begin{array}{l}\text { Skor } \\
\text { Similarity }\end{array}$ & Usual Name & SMILES \\
\hline \multirow[t]{2}{*}{0.824} & Carboprost & $\mathrm{CCCCC}[\mathrm{C} @](\mathrm{C})(\mathrm{O}) \backslash \mathrm{C}=\mathrm{C} \backslash[\mathrm{C} @ \mathrm{H}] 1[\mathrm{C} @ @ \mathrm{H}](\mathrm{O}) \mathrm{C}[\mathrm{C} @ \mathrm{H}]($ \\
\hline & Tromethamine & $\mathrm{O})[\mathrm{C} @ @ \mathrm{H}] 1 \mathrm{C} \backslash \mathrm{C}=\mathrm{C} / \mathrm{CCCC}(\mathrm{O})=\mathrm{O}$ \\
\hline \multirow[t]{2}{*}{0.812} & Rosuvastatin & $\mathrm{CC}(\mathrm{C}) \mathrm{C} 1=\mathrm{NC}(=\mathrm{NC}(\mathrm{C} 2=\mathrm{CC}=\mathrm{C}(\mathrm{F}) \mathrm{C}=\mathrm{C} 2)=\mathrm{C} 1 \backslash \mathrm{C}=\mathrm{C} \backslash[\mathrm{C} @$ \\
\hline & & $@ \mathrm{H}](\mathrm{O}) \mathrm{C}[\mathrm{C} @ @ \mathrm{H}](\mathrm{O}) \mathrm{CC}(\mathrm{O})=\mathrm{O}) \mathrm{N}(\mathrm{C}) \mathrm{S}(\mathrm{C})(=\mathrm{O})=\mathrm{O}$ \\
\hline \multirow[t]{2}{*}{0.810} & Fexofenadine & $\mathrm{CC}(\mathrm{C})(\mathrm{C}(\mathrm{O})=\mathrm{O}) \mathrm{C} 1=\mathrm{CC}=\mathrm{C}(\mathrm{C}=\mathrm{C} 1) \mathrm{C}(\mathrm{O}) \mathrm{CCCN} 1 \mathrm{CCC}(\mathrm{CC}$ \\
\hline & & 1) $\mathrm{C}(\mathrm{O})(\mathrm{C} 1=\mathrm{CC}=\mathrm{CC}=\mathrm{C} 1) \mathrm{C} 1=\mathrm{CC}=\mathrm{CC}=\mathrm{C} 1$ \\
\hline \multirow[t]{2}{*}{0.808} & Treprostinil & [H][C@]12C[C@@H](O)[C@H](CC[C@@H](O)CCCCC) \\
\hline & & {$[\mathrm{C} @ @] 1([\mathrm{H}]) \mathrm{CC} 1=\mathrm{CC}=\mathrm{CC}(\mathrm{OCC}(\mathrm{O})=\mathrm{O})=\mathrm{C} 1 \mathrm{C} 2$} \\
\hline \multirow[t]{2}{*}{0.803} & Atorvastatin & $C C(C) C 1=C(C(=O) N C 2=C C=C C=C 2) C(=C(N 1 C C C(O)$ \\
\hline & & $\mathrm{CC}(\mathrm{O}) \mathrm{CC}(\mathrm{O})=\mathrm{O}) \mathrm{C} 1=\mathrm{CC}=\mathrm{C}(\mathrm{F}) \mathrm{C}=\mathrm{C} 1) \mathrm{C} 1=\mathrm{CC}=\mathrm{CC}=\mathrm{C} 1$ \\
\hline \multirow[t]{2}{*}{0.798} & Dinoprost & $\mathrm{CCCCC}[\mathrm{C} @ \mathrm{H}](\mathrm{O}) \backslash \mathrm{C}=\mathrm{C} \backslash[\mathrm{C} @ \mathrm{H}] 1[\mathrm{C} @ \mathrm{H}](\mathrm{O}) \mathrm{C}[\mathrm{C} @ \mathrm{H}](\mathrm{O})$ \\
\hline & Tromethamine & {$[\mathrm{C} @ @ \mathrm{H}] 1 \mathrm{C} \backslash \mathrm{C}=\mathrm{C} / \mathrm{CCCC}(\mathrm{O})=\mathrm{O}$} \\
\hline \multirow[t]{2}{*}{0.798} & Candoxatril & COCCOC[C@H](CC1(CCCC1)C(=O)N[C@H]1CC[C@ \\
\hline & & $\mathrm{H}](\mathrm{CC} 1) \mathrm{C}(\mathrm{O})=\mathrm{O}) \mathrm{C}(=\mathrm{O}) \mathrm{OC} 1=\mathrm{CC}=\mathrm{C} 2 \mathrm{CCCC} 2=\mathrm{C} 1$ \\
\hline 0.796 & Dinoprostone & $\begin{array}{l}\mathrm{CCCCC}[\mathrm{C} @ \mathrm{H}](\mathrm{O}) \backslash \mathrm{C}=\mathrm{C} \backslash[\mathrm{C} @ \mathrm{H}] 1[\mathrm{C} @ \mathrm{H}](\mathrm{O}) \mathrm{CC}(=\mathrm{O})[\mathrm{C} @ \\
@ \mathrm{H}] 1 \mathrm{C} \backslash \mathrm{C}=\mathrm{C} / \mathrm{CCCC}(\mathrm{O})=\mathrm{O}\end{array}$ \\
\hline 0.793 & Alprostadil & $\begin{array}{l}\mathrm{CCCCC}[\mathrm{C} @ \mathrm{H}](\mathrm{O}) \mathrm{C}=\mathrm{C}[\mathrm{C} @ \mathrm{H}] 1[\mathrm{C} @ \mathrm{H}](\mathrm{O}) \mathrm{CC}(=\mathrm{O})[\mathrm{C} @ @ \\
\mathrm{H}] 1 \mathrm{CCCCCCC}(\mathrm{O})=\mathrm{O}\end{array}$ \\
\hline 0.770 & Bepotastine & $\begin{array}{l}\mathrm{OC}(=\mathrm{O}) \mathrm{CCCN} 1 \mathrm{CCC}(\mathrm{CC} 1) \mathrm{OC}(\mathrm{C} 1=\mathrm{CC}=\mathrm{C}(\mathrm{Cl}) \mathrm{C}=\mathrm{C} 1) \mathrm{C} 1 \\
=\mathrm{NC}=\mathrm{CC}=\mathrm{C} 1\end{array}$ \\
\hline \multirow[t]{3}{*}{0.767} & Cholic Acid & {$[\mathrm{H}][\mathrm{C} @ @](\mathrm{C})(\mathrm{CCC}(\mathrm{O})=\mathrm{O})[\mathrm{C} @ @] 1([\mathrm{H}]) \mathrm{CC}[\mathrm{C} @ @] 2([\mathrm{H}])[$} \\
\hline & & $\mathrm{C} @] 3([\mathrm{H}])[\mathrm{C} @]([\mathrm{H}])(\mathrm{O}) \mathrm{C}[\mathrm{C} @] 4([\mathrm{H}]) \mathrm{C}[\mathrm{C} @]([\mathrm{H}])(\mathrm{O}) \mathrm{CC}[$ \\
\hline & & $\mathrm{C} @] 4(\mathrm{C})[\mathrm{C} @ @] 3([\mathrm{H}]) \mathrm{C}[\mathrm{C} @]([\mathrm{H}])(\mathrm{O})[\mathrm{C} @] 12 \mathrm{C}$ \\
\hline \multirow[t]{2}{*}{0.766} & Epoprostenol & {$[\mathrm{H}][\mathrm{C} @] 12 \mathrm{C}[\mathrm{C} @ @ \mathrm{H}](\mathrm{O})[\mathrm{C} @ \mathrm{H}](\backslash \mathrm{C}=\mathrm{C} \backslash[\mathrm{C} @ @ \mathrm{H}](\mathrm{O}) \mathrm{CCC}$} \\
\hline & & $\mathrm{CC})[\mathrm{C} @ @] 1([\mathrm{H}]) \mathrm{CC}(\mathrm{O} 2)=\mathrm{CCCCC}(\mathrm{O})=\mathrm{O}$ \\
\hline \multirow[t]{2}{*}{0.763} & Benzylpenicilloyl & {$[\mathrm{H}] \mathrm{N}[\mathrm{C} @ \mathrm{H}](\mathrm{CCCCNC}(=\mathrm{O}) \mathrm{C}(\mathrm{NC}(=\mathrm{O}) \mathrm{CC} 1=\mathrm{CC}=\mathrm{CC}=\mathrm{C}$} \\
\hline & Polylysine & 1) $[\mathrm{C} @] 1([\mathrm{H}]) \mathrm{N}[\mathrm{C} @ @ \mathrm{H}](\mathrm{C}(\mathrm{O})=\mathrm{O}) \mathrm{C}(\mathrm{C})(\mathrm{C}) \mathrm{S} 1) \mathrm{C}(\mathrm{O})=\mathrm{O}$ \\
\hline 0.763 & Montelukast & $\begin{array}{l}\mathrm{CC}(\mathrm{C})(\mathrm{O}) \mathrm{C} 1=\mathrm{C}(\mathrm{CC}[\mathrm{C} @ @ \mathrm{H}](\mathrm{SCC} 2(\mathrm{CC}(\mathrm{O})=\mathrm{O}) \mathrm{CC} 2) \mathrm{C} 2= \\
\mathrm{CC}(\backslash \mathrm{C}=\mathrm{C} \backslash \mathrm{C} 3=\mathrm{CC}=\mathrm{C} 4 \mathrm{C}=\mathrm{CC}(\mathrm{Cl})=\mathrm{CC} 4=\mathrm{N} 3)=\mathrm{CC}=\mathrm{C} 2) \mathrm{C} \\
=\mathrm{CC}=\mathrm{C} 1\end{array}$ \\
\hline 0.763 & Cetirizine & $\begin{array}{l}\mathrm{OC}(=\mathrm{O}) \mathrm{COCCN} 1 \mathrm{CCN}(\mathrm{CC} 1) \mathrm{C}(\mathrm{C} 1=\mathrm{CC}=\mathrm{CC}=\mathrm{C} 1) \mathrm{C} 1=\mathrm{CC} \\
=\mathrm{C}(\mathrm{Cl}) \mathrm{C}=\mathrm{C} 1\end{array}$ \\
\hline 0.761 & Gentamicin & $\begin{array}{l}\mathrm{CNC}(\mathrm{C}) \mathrm{C} 1 \mathrm{CCC}(\mathrm{N}) \mathrm{C}(\mathrm{OC} 2 \mathrm{C}(\mathrm{N}) \mathrm{CC}(\mathrm{N}) \mathrm{C}(\mathrm{OC} 3 \mathrm{OCC}(\mathrm{C})(\mathrm{O} \\
) \mathrm{C}(\mathrm{NC}) \mathrm{C} 3 \mathrm{O}) \mathrm{C} 2 \mathrm{O}) \mathrm{O} 1\end{array}$ \\
\hline 0.760 & Alvimopan & $\begin{array}{l}\mathrm{C}[\mathrm{C} @ \mathrm{H}] 1 \mathrm{CN}(\mathrm{C}[\mathrm{C} @ \mathrm{H}](\mathrm{CC} 2=\mathrm{CC}=\mathrm{CC}=\mathrm{C} 2) \mathrm{C}(=\mathrm{O}) \mathrm{NCC}(\mathrm{O} \\
)=\mathrm{O}) \mathrm{CC}[\mathrm{C} @ @] 1(\mathrm{C}) \mathrm{C} 1=\mathrm{CC}(\mathrm{O})=\mathrm{CC}=\mathrm{C} 1\end{array}$ \\
\hline 0.760 & Tiagabine & $\begin{array}{l}\mathrm{CC} 1=\mathrm{C}(\mathrm{SC}=\mathrm{C} 1) \mathrm{C}(=\mathrm{CCCN} 1 \mathrm{CCC}[\mathrm{C} @ \mathrm{H}](\mathrm{C} 1) \mathrm{C}(\mathrm{O})=\mathrm{O}) \mathrm{C} 1 \\
=\mathrm{C}(\mathrm{C}) \mathrm{C}=\mathrm{CS} 1\end{array}$ \\
\hline 0.755 & Olopatadine & $\begin{array}{l}\mathrm{CN}(\mathrm{C}) \mathrm{CC} \backslash \mathrm{C}=\mathrm{C} 1 \backslash \mathrm{C} 2=\mathrm{C}(\mathrm{COC} 3=\mathrm{C} 1 \mathrm{C}=\mathrm{C}(\mathrm{CC}(\mathrm{O})=\mathrm{O}) \mathrm{C}=\mathrm{C} \\
\text { 3) } \mathrm{C}=\mathrm{CC}=\mathrm{C} 2\end{array}$ \\
\hline \multirow[t]{2}{*}{0.753} & Mezlocillin & {$[\mathrm{H}][\mathrm{C} @] 12 \mathrm{SC}(\mathrm{C})(\mathrm{C})[\mathrm{C} @ @ \mathrm{H}](\mathrm{N} 1 \mathrm{C}(=\mathrm{O})[\mathrm{C} @ \mathrm{H}] 2 \mathrm{NC}(=\mathrm{O})[$} \\
\hline & & $\begin{array}{l}\mathrm{C} @ \mathrm{H}](\mathrm{NC}(=\mathrm{O}) \mathrm{N} 1 \mathrm{CCN}(\mathrm{C} 1=\mathrm{O}) \mathrm{S}(\mathrm{C})(=\mathrm{O})=\mathrm{O}) \mathrm{C} 1=\mathrm{CC}=\mathrm{CC} \\
=\mathrm{C} 1) \mathrm{C}(\mathrm{O})=\mathrm{O}\end{array}$ \\
\hline
\end{tabular}


MEDFARM: Jurnal Farmasi dan Kesehatan, Vol.10, No.2, Des 2021, Hal, 65-74

e-ISSN : 2715-9957

p-ISSN: 2354-8487

\begin{tabular}{|c|c|c|}
\hline 0.751 & Difenoxin & $\begin{array}{l}\mathrm{OC}(=\mathrm{O}) \mathrm{C} 1(\mathrm{CCN}(\mathrm{CCC}(\mathrm{C \# N})(\mathrm{C} 2=\mathrm{CC}=\mathrm{CC}=\mathrm{C} 2) \mathrm{C} 2=\mathrm{CC}= \\
\mathrm{CC}=\mathrm{C} 2) \mathrm{CC} 1) \mathrm{C} 1=\mathrm{CC}=\mathrm{CC}=\mathrm{C} 1\end{array}$ \\
\hline 0.747 & Mitoxantrone & $\begin{array}{l}\text { OCCNCCNC } 1=C C=C(N C C N C C O) C 2=C 1 C(=O) C 1=C( \\
C(O)=C C=C 1 O) C 2=O\end{array}$ \\
\hline 0.746 & Fluvastatin & $\begin{array}{l}\mathrm{CC}(\mathrm{C}) \mathrm{N} 1 \mathrm{C}(\backslash \mathrm{C}=\mathrm{C} \backslash[\mathrm{C} @ @ \mathrm{H}](\mathrm{O}) \mathrm{C}[\mathrm{C} @ @ \mathrm{H}](\mathrm{O}) \mathrm{CC}(\mathrm{O})=\mathrm{O}) \\
=\mathrm{C}(\mathrm{C} 2=\mathrm{CC}=\mathrm{CC}=\mathrm{C} 12) \mathrm{C} 1=\mathrm{CC}=\mathrm{C}(\mathrm{F}) \mathrm{C}=\mathrm{C} 1\end{array}$ \\
\hline 0.742 & Ceftazidime & $\begin{array}{l}{[\mathrm{H}][\mathrm{C} @] 12 \mathrm{SCC}(\mathrm{C}[\mathrm{N}+] 3=\mathrm{CC}=\mathrm{CC}=\mathrm{C} 3)=\mathrm{C}(\mathrm{N} 1 \mathrm{C}(=\mathrm{O})[\mathrm{C} @} \\
\mathrm{H}] 2 \mathrm{NC}(=\mathrm{O}) \mathrm{C}(=\mathrm{N} / \mathrm{OC}(\mathrm{C})(\mathrm{C}) \mathrm{C}(\mathrm{O})=\mathrm{O}) \backslash \mathrm{C} 1=\mathrm{CSC}(\mathrm{N})=\mathrm{N} 1 \\
) \mathrm{C}([\mathrm{O}-])=\mathrm{O}\end{array}$ \\
\hline 0.738 & Pravastatin & $\begin{array}{l}{[\mathrm{H}][\mathrm{C} @] 12[\mathrm{C} @ \mathrm{H}](\mathrm{C}[\mathrm{C} @ \mathrm{H}](\mathrm{O}) \mathrm{C}=\mathrm{C} 1 \mathrm{C}=\mathrm{C}[\mathrm{C} @ \mathrm{H}](\mathrm{C})[\mathrm{C} @} \\
@ \mathrm{H}] 2 \mathrm{CC}[\mathrm{C} @ \mathrm{H}](\mathrm{O}) \mathrm{C}[\mathrm{C} @ @ \mathrm{H}](\mathrm{O}) \mathrm{CC}(\mathrm{O})=\mathrm{O}) \mathrm{OC}(=\mathrm{O})[\mathrm{C} \\
@ @ \mathrm{H}](\mathrm{C}) \mathrm{CC}\end{array}$ \\
\hline 0.734 & Cyclacillin & $\begin{array}{l}{[\mathrm{H}][\mathrm{C} @] 12 \mathrm{SC}(\mathrm{C})(\mathrm{C})[\mathrm{C} @ @ \mathrm{H}](\mathrm{N} 1 \mathrm{C}(=\mathrm{O})[\mathrm{C} @ \mathrm{H}] 2 \mathrm{NC}(=\mathrm{O})} \\
\mathrm{C} 1(\mathrm{~N}) \mathrm{CCCCC} 1) \mathrm{C}(\mathrm{O})=\mathrm{O}\end{array}$ \\
\hline 0.733 & Levocabastine & $\begin{array}{l}\mathrm{C}[\mathrm{C} @ @ \mathrm{H}] 1 \mathrm{CN}(\mathrm{CC}[\mathrm{C} @] 1(\mathrm{C}(\mathrm{O})=\mathrm{O}) \mathrm{C} 1=\mathrm{CC}=\mathrm{CC}=\mathrm{C} 1) \mathrm{C} 1 \mathrm{C} \\
\mathrm{CC}(\mathrm{CC} 1)(\mathrm{C} \# \mathrm{~N}) \mathrm{C} 1=\mathrm{CC}=\mathrm{C}(\mathrm{F}) \mathrm{C}=\mathrm{C} 1\end{array}$ \\
\hline 0.733 & Mycophenolic acid & $\begin{array}{l}\mathrm{COC} 1=\mathrm{C}(\mathrm{C}) \mathrm{C} 2=\mathrm{C}(\mathrm{C}(=\mathrm{O}) \mathrm{OC} 2) \mathrm{C}(\mathrm{O})=\mathrm{C} 1 \mathrm{C} \backslash \mathrm{C}=\mathrm{C}(/ \mathrm{C}) \mathrm{CC} \\
\mathrm{C}(\mathrm{O})=\mathrm{O}\end{array}$ \\
\hline 0.731 & Natamycin & $\begin{array}{l}\mathrm{C}[\mathrm{C} @ \mathrm{H}] 1 \mathrm{OC}(\mathrm{O}[\mathrm{C} @ @ \mathrm{H}] 2 \mathrm{C}[\mathrm{C} @ @ \mathrm{H}] 3 \mathrm{O}[\mathrm{C} @ @](\mathrm{O})(\mathrm{C}[\mathrm{C} @ \\
\mathrm{H}](\mathrm{O})[\mathrm{C} @ \mathrm{H}] 3 \mathrm{C}(\mathrm{O})=\mathrm{O}) \mathrm{C}[\mathrm{C} @ @ \mathrm{H}](\mathrm{O}) \mathrm{C}[\mathrm{C} @ \mathrm{H}] 3 \mathrm{O}[\mathrm{C} @ @ \mathrm{H} \\
] 3 \backslash \mathrm{C}=\mathrm{C} \backslash \mathrm{C}(=\mathrm{O}) \mathrm{O}[\mathrm{C} @ \mathrm{H}](\mathrm{C}) \mathrm{C} \backslash \mathrm{C}=\mathrm{C} \backslash \mathrm{C}=\mathrm{C} \backslash \mathrm{C}=\mathrm{C} \backslash \mathrm{C}=\mathrm{C} \backslash 2 \\
)[\mathrm{C} @ \mathrm{H}](\mathrm{O})[\mathrm{C} @ \mathrm{H}](\mathrm{N})[\mathrm{C} @ \mathrm{H}] 1 \mathrm{O}\end{array}$ \\
\hline 0.731 & Piperacillin & $\begin{array}{l}{[\mathrm{H}][\mathrm{C} @] 12 \mathrm{SC}(\mathrm{C})(\mathrm{C})[\mathrm{C} @ @ \mathrm{H}](\mathrm{N} 1 \mathrm{C}(=\mathrm{O})[\mathrm{C} @ \mathrm{H}] 2 \mathrm{NC}(=\mathrm{O})[} \\
\mathrm{C} @ \mathrm{H}](\mathrm{NC}(=\mathrm{O}) \mathrm{N} 1 \mathrm{CCN}(\mathrm{CC}) \mathrm{C}(=\mathrm{O}) \mathrm{C} 1=\mathrm{O}) \mathrm{C} 1=\mathrm{CC}=\mathrm{CC}= \\
\mathrm{C} 1) \mathrm{C}(\mathrm{O})=\mathrm{O}\end{array}$ \\
\hline 0.727 & Ampicillin & $\begin{array}{l}{[\mathrm{H}][\mathrm{C} @] 12 \mathrm{SC}(\mathrm{C})(\mathrm{C})[\mathrm{C} @ @ \mathrm{H}](\mathrm{N} 1 \mathrm{C}(=\mathrm{O})[\mathrm{C} @ \mathrm{H}] 2 \mathrm{NC}(=\mathrm{O})[} \\
\mathrm{C} @ \mathrm{H}](\mathrm{N}) \mathrm{C} 1=\mathrm{CC}=\mathrm{CC}=\mathrm{C} 1) \mathrm{C}(\mathrm{O})=\mathrm{O}\end{array}$ \\
\hline 0.723 & Pitavastatin & $\begin{array}{l}\mathrm{O}[\mathrm{C} @ \mathrm{H}](\mathrm{C}[\mathrm{C} @ \mathrm{H}](\mathrm{O}) \backslash \mathrm{C}=\mathrm{C} \backslash \mathrm{C} 1=\mathrm{C}(\mathrm{N}=\mathrm{C} 2 \mathrm{C}=\mathrm{CC}=\mathrm{CC} 2= \\
\mathrm{C} 1 \mathrm{C} 1=\mathrm{CC}=\mathrm{C}(\mathrm{F}) \mathrm{C}=\mathrm{C} 1) \mathrm{C} 1 \mathrm{CC} 1) \mathrm{CC}(\mathrm{O})=\mathrm{O}\end{array}$ \\
\hline 0.722 & Moxifloxacin & $\begin{array}{l}{[\mathrm{H}][\mathrm{C} @] 12 \mathrm{CN}(\mathrm{C}[\mathrm{C} @ @] 1([\mathrm{H}]) \mathrm{NCCC} 2) \mathrm{C} 1=\mathrm{C}(\mathrm{F}) \mathrm{C}=\mathrm{C} 2 \mathrm{C}(} \\
=\mathrm{O}) \mathrm{C}(=\mathrm{CN}(\mathrm{C} 3 \mathrm{CC} 3) \mathrm{C} 2=\mathrm{C} 1 \mathrm{OC}) \mathrm{C}(\mathrm{O})=\mathrm{O}\end{array}$ \\
\hline 0.720 & $\begin{array}{l}\text { Chenodeoxycholic } \\
\text { acid }\end{array}$ & $\begin{array}{l}{[\mathrm{H}][\mathrm{C} @ @] 1(\mathrm{CC}[\mathrm{C} @ @] 2([\mathrm{H}])[\mathrm{C} @] 3([\mathrm{H}])[\mathrm{C} @ \mathrm{H}](\mathrm{O}) \mathrm{C}[\mathrm{C} @]} \\
4([\mathrm{H}]) \mathrm{C}[\mathrm{C} @ \mathrm{H}](\mathrm{O}) \mathrm{CC}[\mathrm{C} @] 4(\mathrm{C})[\mathrm{C} @] 3([\mathrm{H}]) \mathrm{CC}[\mathrm{C} @] 12 \mathrm{C}) \\
{[\mathrm{C} @ \mathrm{H}](\mathrm{C}) \mathrm{CCC}(\mathrm{O})=\mathrm{O}}\end{array}$ \\
\hline 0.718 & Besifloxacin & $\begin{array}{l}\mathrm{N}[\mathrm{C} @ @ \mathrm{H}] 1 \mathrm{CCCCN}(\mathrm{C} 1) \mathrm{C} 1=\mathrm{C}(\mathrm{F}) \mathrm{C}=\mathrm{C} 2 \mathrm{C}(=\mathrm{O}) \mathrm{C}(=\mathrm{CN}(\mathrm{C} 3 \\
\mathrm{CC} 3) \mathrm{C} 2=\mathrm{C} 1 \mathrm{Cl}) \mathrm{C}(\mathrm{O})=\mathrm{O}\end{array}$ \\
\hline 0.716 & Cefradine & $\begin{array}{l}{[\mathrm{H}][\mathrm{C} @] 12 \mathrm{SCC}(\mathrm{C})=\mathrm{C}(\mathrm{N} 1 \mathrm{C}(=\mathrm{O})[\mathrm{C} @ \mathrm{H}] 2 \mathrm{NC}(=\mathrm{O})[\mathrm{C} @ \mathrm{H}](} \\
\mathrm{N}) \mathrm{C} 1=\mathrm{CCC}=\mathrm{CC} 1) \mathrm{C}(\mathrm{O})=\mathrm{O}\end{array}$ \\
\hline 0.716 & Sparfloxacin & $\begin{array}{l}\mathrm{C}[\mathrm{C} @ \mathrm{H}] 1 \mathrm{CN}(\mathrm{C}[\mathrm{C} @ @ \mathrm{H}](\mathrm{C}) \mathrm{N} 1) \mathrm{C} 1=\mathrm{C}(\mathrm{F}) \mathrm{C}(\mathrm{N})=\mathrm{C} 2 \mathrm{C}(=\mathrm{O}) \\
\mathrm{C}(=\mathrm{CN}(\mathrm{C} 3 \mathrm{CC} 3) \mathrm{C} 2=\mathrm{C} 1 \mathrm{~F}) \mathrm{C}(\mathrm{O})=\mathrm{O}\end{array}$ \\
\hline 0.716 & Repaglinide & $\begin{array}{l}C C O C 1=C(C=C C(C C(=O) N[C @ @ H](C C(C) C) C 2=C(C \\
=C C=C 2) N 2 C C C C C 2)=C 1) C(O)=O\end{array}$ \\
\hline 0.715 & Amoxicillin & $\begin{array}{l}{[\mathrm{H}][\mathrm{C} @] 12 \mathrm{SC}(\mathrm{C})(\mathrm{C})[\mathrm{C} @ @ \mathrm{H}](\mathrm{N} 1 \mathrm{C}(=\mathrm{O})[\mathrm{C} @ \mathrm{H}] 2 \mathrm{NC}(=\mathrm{O})[} \\
\mathrm{C} @ \mathrm{H}](\mathrm{N}) \mathrm{C} 1=\mathrm{CC}=\mathrm{C}(\mathrm{O}) \mathrm{C}=\mathrm{C} 1) \mathrm{C}(\mathrm{O})=\mathrm{O}\end{array}$ \\
\hline 0.713 & Deferasirox & $\begin{array}{l}\mathrm{OC}(=\mathrm{O}) \mathrm{C} 1=\mathrm{CC}=\mathrm{C}(\mathrm{C}=\mathrm{C} 1) \mathrm{N} 1 \mathrm{~N}=\mathrm{C}(\mathrm{N}=\mathrm{C} 1 \mathrm{C} 1=\mathrm{CC}=\mathrm{CC}=\mathrm{C} \\
1 \mathrm{O}) \mathrm{C} 1=\mathrm{CC}=\mathrm{CC}=\mathrm{C} 1 \mathrm{O}\end{array}$ \\
\hline 0.709 & Fosamprenavir & $\begin{array}{l}\mathrm{CC}(\mathrm{C}) \mathrm{CN}(\mathrm{C}[\mathrm{C} @ @ \mathrm{H}](\mathrm{OP}(\mathrm{O})(\mathrm{O})=\mathrm{O})[\mathrm{C} @ \mathrm{H}](\mathrm{CC} 1=\mathrm{CC}=\mathrm{C} \\
\mathrm{C}=\mathrm{C} 1) \mathrm{NC}(=\mathrm{O}) \mathrm{O}[\mathrm{C} @ \mathrm{H}] 1 \mathrm{CCOC} 1) \mathrm{S}(=\mathrm{O})(=\mathrm{O}) \mathrm{C} 1=\mathrm{CC}=\mathrm{C}( \\
\mathrm{N}) \mathrm{C}=\mathrm{C} 1\end{array}$ \\
\hline 0.709 & Leucovorin & $\begin{array}{l}\mathrm{NC} 1=\mathrm{NC} 2=\mathrm{C}(\mathrm{N}(\mathrm{C}=\mathrm{O})[\mathrm{C} @ @ \mathrm{H}](\mathrm{CNC}=\mathrm{CC}=\mathrm{C}(\mathrm{C}=\mathrm{C} 3) \mathrm{C}( \\
=\mathrm{O}) \mathrm{N}[\mathrm{C} @ @ \mathrm{H}](\mathrm{CCC}(\mathrm{O})=\mathrm{O}) \mathrm{C}(\mathrm{O})=\mathrm{O}) \mathrm{CN} 2) \mathrm{C}(=\mathrm{O}) \mathrm{N} 1\end{array}$ \\
\hline 0.707 & Azido & $\begin{array}{l}{[\mathrm{H}][\mathrm{C} @] 12 \mathrm{SC}(\mathrm{C})(\mathrm{C})[\mathrm{C} @ @ \mathrm{H}](\mathrm{N} 1 \mathrm{C}(=\mathrm{O})[\mathrm{C} @ \mathrm{H}] 2 \mathrm{NC}(=\mathrm{O})[} \\
\mathrm{C} @ \mathrm{H}]([\mathrm{N}-][\mathrm{N}+] \# \mathrm{~N}) \mathrm{C} 1=\mathrm{CC}=\mathrm{CC}=\mathrm{C} 1) \mathrm{C}(\mathrm{O})=\mathrm{O}\end{array}$ \\
\hline
\end{tabular}


MEDFARM: Jurnal Farmasi dan Kesehatan, Vol.10, No.2, Des 2021, Hal, 65-74

e-ISSN : 2715-9957

p-ISSN: 2354-8487

\begin{tabular}{|c|c|c|}
\hline 0.707 & $\begin{array}{l}\text { Ursodeoxycholic } \\
\text { acid }\end{array}$ & $\begin{array}{l}{[\mathrm{H}][\mathrm{C} @ @] 1(\mathrm{CC}[\mathrm{C} @ @] 2([\mathrm{H}])[\mathrm{C} @] 3([\mathrm{H}])[\mathrm{C} @ @ \mathrm{H}](\mathrm{O}) \mathrm{C}[\mathrm{C}} \\
@] 4([\mathrm{H}]) \mathrm{C}[\mathrm{C} @ \mathrm{H}](\mathrm{O}) \mathrm{CC}[\mathrm{C} @] 4(\mathrm{C})[\mathrm{C} @ @] 3([\mathrm{H}]) \mathrm{CC}[\mathrm{C} @] 12 \\
\mathrm{C})[\mathrm{C} @ \mathrm{H}](\mathrm{C}) \mathrm{CCC}(\mathrm{O})=\mathrm{O}\end{array}$ \\
\hline 0.707 & Netilmicin & $\begin{array}{l}\mathrm{CCN}[\mathrm{C} @ @ \mathrm{H}] 1 \mathrm{C}[\mathrm{C} @ \mathrm{H}](\mathrm{N})[\mathrm{C} @ @ \mathrm{H}](\mathrm{O}[\mathrm{C} @ \mathrm{H}] 2 \mathrm{OC}(\mathrm{CN})= \\
\mathrm{CC}[\mathrm{C} @ \mathrm{H}] 2 \mathrm{~N})[\mathrm{C} @ \mathrm{H}](\mathrm{O})[\mathrm{C} @ \mathrm{H}] 1 \mathrm{O}[\mathrm{C} @ \mathrm{H}] 1 \mathrm{OC}[\mathrm{C} @ \mathrm{H}](\mathrm{O})[ \\
\mathrm{C} @ \mathrm{H}](\mathrm{NC})[\mathrm{C} @ @] 1(\mathrm{C}) \mathrm{O}\end{array}$ \\
\hline 0.706 & Cephalexin & $\begin{array}{l}{[\mathrm{H}][\mathrm{C} @ 12 \mathrm{SCC}(\mathrm{C})=\mathrm{C}(\mathrm{N} 1 \mathrm{C}(=\mathrm{O})[\mathrm{C} @ \mathrm{H}] 2 \mathrm{NC}(=\mathrm{O})[\mathrm{C} @ \mathrm{H}](} \\
\mathrm{N}) \mathrm{C} 1=\mathrm{CC}=\mathrm{CC}=\mathrm{C} 1) \mathrm{C}(\mathrm{O})=\mathrm{O}\end{array}$ \\
\hline 0.704 & Cefpiramide & $\begin{array}{l}{[\mathrm{H}][\mathrm{C} @] 12 \mathrm{SCC}(\mathrm{CSC} 3=\mathrm{NN}=\mathrm{NN} 3 \mathrm{C})=\mathrm{C}(\mathrm{N} 1 \mathrm{C}(=\mathrm{O})[\mathrm{C} @ @]} \\
2([\mathrm{H}]) \mathrm{NC}(=\mathrm{O})[\mathrm{C} @ \mathrm{H}](\mathrm{NC}(=\mathrm{O}) \mathrm{C} 1=\mathrm{C}(\mathrm{O}) \mathrm{C}=\mathrm{C}(\mathrm{C}) \mathrm{N}=\mathrm{C} 1) \mathrm{C} \\
1=\mathrm{CC}=\mathrm{C}(\mathrm{O}) \mathrm{C}=\mathrm{C} 1) \mathrm{C}(\mathrm{O})=\mathrm{O}\end{array}$ \\
\hline 0.703 & Azlocillin & $\begin{array}{l}{[\mathrm{H}][\mathrm{C} @](\mathrm{NC}(=\mathrm{O}) \mathrm{N} 1 \mathrm{CCNC}=\mathrm{O})(\mathrm{C}(=\mathrm{O}) \mathrm{N}[\mathrm{C} @ @ \mathrm{H}] 1 \mathrm{C}(=} \\
\mathrm{O}) \mathrm{N} 2[\mathrm{C} @ @ \mathrm{H}](\mathrm{C}(\mathrm{O})=\mathrm{O}) \mathrm{C}(\mathrm{C})(\mathrm{C}) \mathrm{S}[\mathrm{C} @] 12[\mathrm{H}]) \mathrm{C} 1=\mathrm{CC}=\mathrm{C} \\
\mathrm{C}=\mathrm{C} 1\end{array}$ \\
\hline 0.703 & Lubiprostone & $\begin{array}{l}{[\mathrm{H}][\mathrm{C} @ @] 12 \mathrm{CC}(=\mathrm{O})[\mathrm{C} @ @ \mathrm{H}](\mathrm{CCCCCCC}(\mathrm{O})=\mathrm{O})[\mathrm{C} @ @] 1} \\
([\mathrm{H}]) \mathrm{CC}[\mathrm{C} @ @](\mathrm{O})(\mathrm{O} 2) \mathrm{C}(\mathrm{F})(\mathrm{F}) \mathrm{CCCC}\end{array}$ \\
\hline 0.703 & Aspartame & $\begin{array}{l}\mathrm{COC}(=\mathrm{O})[\mathrm{C} @ \mathrm{H}](\mathrm{CC} 1=\mathrm{CC}=\mathrm{CC}=\mathrm{C} 1) \mathrm{NC}(=\mathrm{O})[\mathrm{C} @ @ \mathrm{H}](\mathrm{N} \\
) \mathrm{CC}(\mathrm{O})=\mathrm{O}\end{array}$ \\
\hline 0.701 & Eltrombopag & $\begin{array}{l}\mathrm{CC} 1=\mathrm{NN}(\mathrm{C}(=\mathrm{O}) \mathrm{C} 1=\mathrm{NNC} 1=\mathrm{CC}=\mathrm{CC}(\mathrm{C} 2=\mathrm{CC}(=\mathrm{CC}=\mathrm{C} 2) \\
\mathrm{C}(\mathrm{O})=\mathrm{O})=\mathrm{C} 1 \mathrm{O}) \mathrm{C} 1=\mathrm{CC}(\mathrm{C})=\mathrm{C}(\mathrm{C}) \mathrm{C}=\mathrm{C} 1\end{array}$ \\
\hline 0.701 & Folic Acid & $\begin{array}{l}\mathrm{NC} 1=\mathrm{NC} 2=\mathrm{NC}=\mathrm{C}(\mathrm{CNC} 3=\mathrm{CC}=\mathrm{C}(\mathrm{C}=\mathrm{C} 3) \mathrm{C}(=\mathrm{O}) \mathrm{N}[\mathrm{C} @ @ \\
\mathrm{H}](\mathrm{CCC}(\mathrm{O})=\mathrm{O}) \mathrm{C}(\mathrm{O})=\mathrm{O}) \mathrm{N}=\mathrm{C} 2 \mathrm{C}(=\mathrm{O}) \mathrm{N} 1\end{array}$ \\
\hline 0.700 & Meropenem & $\begin{array}{l}{[\mathrm{H}][\mathrm{C} @] 1([\mathrm{C} @ @ \mathrm{H}](\mathrm{C}) \mathrm{O}) \mathrm{C}(=\mathrm{O}) \mathrm{N} 2 \mathrm{C}(\mathrm{C}(\mathrm{O})=\mathrm{O})=\mathrm{C}(\mathrm{S}[\mathrm{C} @ @} \\
\mathrm{H}] 3 \mathrm{CN}[\mathrm{C} @ \mathrm{H}](\mathrm{C}) \mathrm{C}(=\mathrm{O}) \mathrm{N}(\mathrm{C}) \mathrm{C})[\mathrm{C} @ \mathrm{H}](\mathrm{C})[\mathrm{C} @] 12[\mathrm{H}]\end{array}$ \\
\hline
\end{tabular}

Berdasarkan tabel 1, diketahui bahwa banyak senyawa yang mirip boceprevir berupa obat antibiotika seperti amoxicillin, ampicilin, meropenem, moxifloxacin dan sebagainya. Kemudian terdapat beberapa golongan lain seperti golongan statin dan turunan dari asam kolik. Menariknya terdapat satu antivirus yaitu fosamprenavir yang merupakan obat untuk terapi infeksi HIV (Wire et al., 2006). Setelah dilakukan validasi metode diperoleh data kurva ROC dimana data tersebut dapat digunakan untuk membedakan dua populasi yang berbeda, dalam hal ini populasi aktif yaitu senyawa boceprevir dan populasi tidak aktif yaitu senyawa perangkap (Triballeau et al., 2005). 
MEDFARM: Jurnal Farmasi dan Kesehatan, Vol.10, No.2, Des 2021, Hal, 65-74 e-ISSN : 2715-9957

p-ISSN: 2354-8487

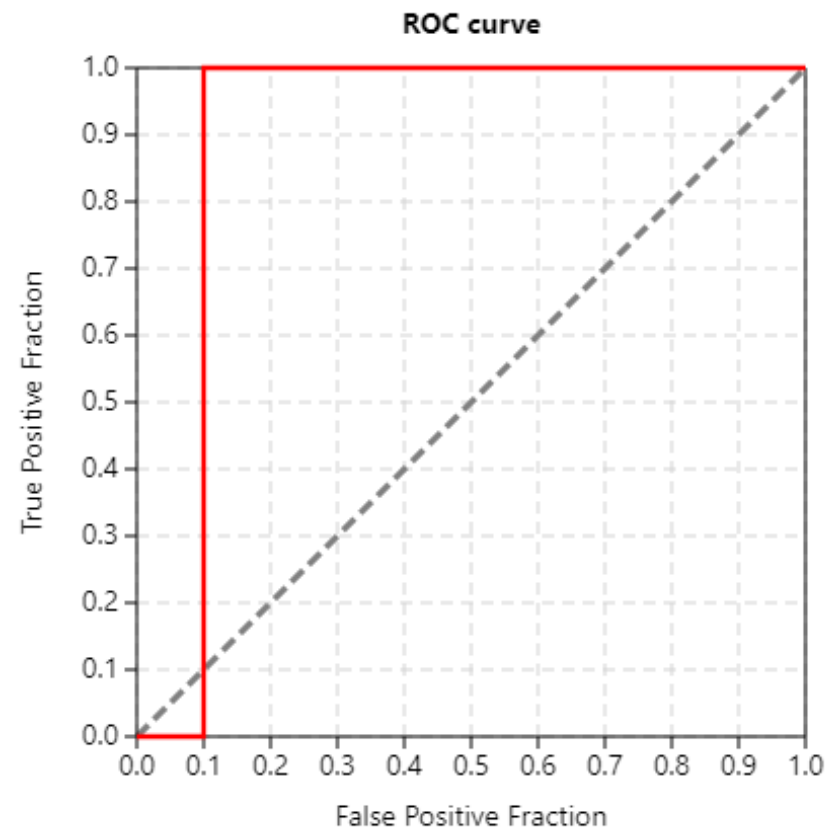

Gambar 1. Kurva ROC dari validasi metode senyawa aktif (boceprevir) dan senyawa tidak aktif (senyawa perangkap)

Dari gambar 1 diketahui bahwa ROC dari validasi metode tersebut adalah sebesar 0.900, dimana artinya metode ini dapat digunakan dengan baik dalam membedakan populasi aktif dan populasi inaktif.

Penambatan molekul pada senyawa senyawa hasil skrining virtual dilakukan dengan cara yang sama seperti langkah pada validasi metode yang kemudian diperoleh binding affinity. Semakin rendah nilai binding affinity menunjukkan kestabilan interaksi antara ligan dengan protein.

Tabel 2. Hasil penambatan molekul senyawa mirip boceprevir

\begin{tabular}{cc}
\hline Nama obat & Binding affinity (kcal/mol) \\
\hline Natamycin & -8.3 \\
Pitavastatin & -8.2 \\
Boceprevir & -7.9 \\
Eltrombopag & -7.9 \\
Sparfloxacin & -7.9 \\
Ceftazidime & -7.6 \\
Moxifloxacin & -7.3 \\
Deferasirox & -7.2 \\
Fluvastatin & -7.2 \\
Mezlocillin & -7.1 \\
Rosuvastatin & -7.0 \\
Besifloxacin & -7.0 \\
\hline
\end{tabular}


MEDFARM: Jurnal Farmasi dan Kesehatan, Vol.10, No.2, Des 2021, Hal, 65-74

e-ISSN : 2715-9957

p-ISSN: 2354-8487

\begin{tabular}{|c|c|}
\hline Azlocillin & -6.8 \\
\hline Folic_acid & -6.8 \\
\hline Olopatadine & -6.8 \\
\hline Piperacillin & -6.7 \\
\hline Atorvastatin & -6.6 \\
\hline Difenoxin & -6.6 \\
\hline Fosamprenavir & -6.6 \\
\hline Leucovorin & -6.6 \\
\hline Levocabastine & -6.6 \\
\hline Montelukast & -6.6 \\
\hline Dinoprostone & -6.5 \\
\hline Benzylpenicilloyl_polylysine & -6.5 \\
\hline Candoxatril & -6.4 \\
\hline Cholic_acid & -6.4 \\
\hline Fexofenadine & -6.4 \\
\hline Cephalexin & -6.4 \\
\hline Chenodeoxycholic_acid & -6.4 \\
\hline Netilmicin & -6.4 \\
\hline Repaglinide & -6.4 \\
\hline Tiagabine & -6.4 \\
\hline Ursodeoxycholic_acid & -6.4 \\
\hline Cefpiramide & -6.3 \\
\hline Mycophenolic_acid & -6.3 \\
\hline Alvimopan & -6.2 \\
\hline Azidocillin & -6.2 \\
\hline Gentamicine & -6.2 \\
\hline Pravastatin & -6.2 \\
\hline Dinoprost_tromethamine & -6.1 \\
\hline Carboprost_tromethamine & -6.1 \\
\hline Mitoxantrone & -6.1 \\
\hline Alprostadil & -6.0 \\
\hline Aspartame & -6.0 \\
\hline Bepotastine & -6.0 \\
\hline Cetirizine & -6.0 \\
\hline Cefradine & -5.9 \\
\hline Lubiprostone & -5.8 \\
\hline Cyclacillin & -5.7 \\
\hline Epoprostenol & -5.7 \\
\hline Meropenem & -5.7 \\
\hline Trepostinil & -5.6 \\
\hline Amoxicillin & -5.6 \\
\hline Ampicillin & -5.6 \\
\hline
\end{tabular}

Dari data binding affinity tersebut diketahui terdapat 2 obat potensial yang memiliki nilai yang lebih rendah dibandingkan boceprevir $(-7,9 \mathrm{kcal} / \mathrm{mol})$, yaitu 
MEDFARM: Jurnal Farmasi dan Kesehatan, Vol.10, No.2, Des 2021, Hal, 65-74

e-ISSN : 2715-9957

p-ISSN: 2354-8487

natamycin dan patavastatin yang masing masing binding affinity nya adalah $-8,3$ $\mathrm{kcal} / \mathrm{mol}$ dan $-8,2 \mathrm{kcal} / \mathrm{mol}$. Nilai binding affinity yang rendah tersebut menunjukkan bahwa kedua obat tersebut dapat berinteraksi secara stabil dengan enzim Mpro dari COVID 19.

Natamycin merupakan antimikroba yang digunakan sebagai pengawet pada makan dan minuman (Davidson dan Doan, 2020). Sementara pitavastatin merupakan golongan statin yang penginduksi Low Density Lipoprotein-Cholesterol (LDL-C) hepatosit yang efektif menurunkan LDL-C dengan dosis yang rendah (Saito, 2011). Berdasarkan penelitian ini, dua kandidat obat tersebut dapat diteliti lebih lanjut untuk dilakukan penggunaan kembali sebagai kandidat obat COVID 19. Namun tetap perlu dilakukan validasi metode dengan senyawa yang lebih banyak lagi agar didapatkan hasil yang lebih baik lagi.

\section{SIMPULAN}

Skrining virtual dengan penambatan molekul dapat memberikan pilihan penggunaan obat sebagai alternatif terapi COVID 19. Validasi metode menunjukkan bahwa metode ini dapat digunakan dengan baik walaupun masih perlu dilakukan penambahan senyawa senyawa aktif lainnya dan penambahan perangkap lainnya dari hasil penelitian secara in vitro. Dari penelitian ini didapatkan dua pilihan alternatif obat COVID 19 pada hambatan enzim Mpro yaitu natamycin dan pitavastatin.

\section{DAFTAR PUSTAKA}

Armstrong, M.S., Finn, P.W., Morris, G.M., Richards, W.G. 2011. Improving the accuracy of ultrafast ligand-based screening: incorporating lipophilicity into ElectroShape as an extra dimension. Journal of Computer-Aided Molecular Design, 25, 785

BPOM. 2020. Informatorium obat COVID 19 di Indonesia. Badan Pengawas Obat dan Makanan

Cusinato, J., Cau, Y., Calvani, A.M., Mori, M. 2020. Repurposing drugs for the management of COVID-19. Expert Opinion on Therapeutic Patents, 31, 295307.

Davidson, P.M., Doan, C. 2020. Natamycin. In Davidson, P.M., Taylor, T.M., David, J.R.D. Antimicrobials in Food, 359-356. CRC Press 
MEDFARM: Jurnal Farmasi dan Kesehatan, Vol.10, No.2, Des 2021, Hal, 65-74

e-ISSN : 2715-9957

p-ISSN: 2354-8487

ElTijani, A., Alsafi, M.Y., Ahmed, A.F. 2019. EasyDockVina: Graphical Interface for Ligand Optimization and High Throughput Virtual Screening with Vina (2.2). Zenodo.

Mysinger, M.M., Carchia, M., Irwin, J.J., Shoichet, B.K. 2012. Directory of Useful Decoys, Enhanced (DUD-E): Better Ligands and Decoys for Better Benchmarking. Journal of Medicinal Chemistry, 55(14), 6582-6594.

Qiao, J., Li, Y.S., Zeng, R., Liu, F.L., Luo, R.H., Huang, C., Wang, Y.F., Zhang, J., Quan, B., Shen, C., Mao, X., Liu, X., Sun, W., Yang, W., Ni, X., Wang, K., $\mathrm{Xu}$, L., Duan, Z.L., Zou, Q.C., Zhang, H.L., Qu, W., Long, Y.H., Li, M.H., Yang, R.C., Liu, X., You, J., Zhou, Y., Yao, R., Li, W.P., Liu, J.M., Chen, P., Liu, Y., Lin, G.F., Yang, X., Zou, J., Li, L., Hu, Y., Lu, G.W., Li, W.M., Wei, Y.Q., Zheng, Y.T., Lei, J., Yang, S. 2021. SARS-CoV-2 M pro inhibitors with antiviral activity in a transgenic mouse model. Science, 371, 1374-1378.

Saito, Y. 2011. Pitavastatin: An overview. Atherosclerosis Supplements, 12(3), 271276.

Sekhar, T. 2021. Molecular Docking and Virtual Screening Based Prediction of Drugs for COVID-19. Combinatorial Chemistry \& High Throughput Screening, 24, 716-728.

Triballeau, N., Acher, F., Brabet, I., Pin, J. P., \& Bertrand, H. O. 2005. Virtual screening workflow development guided by the "receiver operating characteristic" curve approach. Application to high-throughput docking on metabotropic glutamate receptor subtype 4. Journal of medicinal chemistry, 48(7), 2534-2547.

Wire, M.B., Shelton, M.J., Studenberg, S. 2006. Fosamprenavir. Clinical Pharmacokinetics, 45(2), 137-168.

Wu, F., Zhao, S., Yu, B., Chen, Y.M., Wang, W., Song, Z.G., Hu, Y., Tao, Z.W., Tian, J.H., Pei, Y.Y., Yuan, M.L., Zhang, Y.L., Dai, F.H., Liu, Y., Wang, Q.M., Zheng, J.J., Xu, L., Holmes, E.C., Zhang, Y.Z. 2020. A new coronavirus associated with human respiratory disease in China. Nature, $579,265-269$.

Zhang, L., Lin, D., Kusov, Y., Nian, Y., Ma, Q., Wang, J., Brunn, A.v., Leyssen, P., Lanko, K., Neyts, J., Wilde, A.d., Snijder E.J., Liu, H., Hilgenfeld, R. 2020. Alpha-ketoamides as broad-spectrum inhibitors of coronavirus and enterovirus replication Structure-based design, synthesis, and activity assessment. Journal of Medicinal Chemistry, 63, 4562-4578.

Zoete, V., Daina, A., Bovigny, C., Michielin, O. 2016. SwissSimilarity: A Web Tool for Low to Ultra High Throughput Ligand-Based Virtual Screening. Journal of Chemical Information and Modeling, 56(8), 1399-1404. 